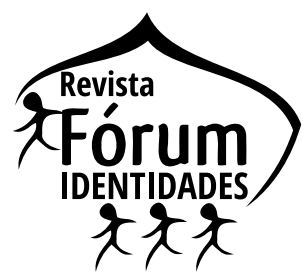

\title{
VIOLÊNCIA DE GÊNERO NA OBRA TAL BRAZIL, QUEER ROMANCE, DE ANTÔNIO DE PÁDUA'
}

GENDER VIOLENCE IN THE WORK

TAL BRAZIL, QUEER ROMANCE, OF ANTÔNIO DE PADUA

\author{
Simiào Mendes Júnior ${ }^{2}$
}

\begin{abstract}
Resumo: Este artigo visa analisar a violência e a colonialidade de gênero no contexto de Brasil colônia através da obra Tal Brazil, Queer Romance - Romance da(s) bistória(s) dos afetos on História do(s) romances(s) dos afetos (2012), do escritor, professor e crítico paraibano Antônio de Pádua, partindo das perspectivas propostas pelos estudos de Linda Hutcheon (1991) sobre a metaficção historiográfica, de Guacira Lopes Louro (2001) e Judith Butler (1999) sobre a teoria queer e de colonialidade de gênero de María Lugones (2008), com o objetivo de refletir a representação social da mulher e do sujeito gay na colônia, visando entender o processo histórico da violência de gênero e de como ela se estende aos dias atuais.
\end{abstract}

Palavras-chave: colonialismo, performatividade, queer, violência de gênero.

\begin{abstract}
This article aims to analyze gender violence and coloniality in the context of colonial Brazil through the work Tal Brazil, Queer Romance - Romance of the story(s) of affections or History of the novel(s) of affections (2012), by the writer, professor and critic from Paraiba Antônio de Pádua, based on the perspectives proposed by the studies of Linda Hutcheon (1991) on historiographic metafiction, Guacira Lopes Louro (2001) and Judith Butler (1999) on queer theory and coloniality of gender by María Lugones (2008), with the aim of reflecting the social representation of women and gay subjects in the colony, aiming to understand the historical process of gender violence and how it extends to the present day.
\end{abstract}

Keywords: colonialism, performativity, queer, gender violence.

\footnotetext{
${ }^{1}$ Artigo recebido em 15 de agosto de 2021 e aceito para publicação em 29 de setembro de 2021.

${ }^{2}$ Doutorando em Estudos Literários pelo programa de pós-graduação em Letras e Linguística da Faculdade de Letras da Universidade Federal de Goiás (UFG) sob a orientação do professor Dr. Pedro Carlos Lousada Fonseca. E-mail: simiao.junior.ufg@gmail.com. ORCID: https://orcid.org/0000-0003-2660-821X. Researcher id: https://researchid.co/simiao.junior.
} 


\section{Considerações iniciais}

Muito já foi dito em estudos e artigos científicos, seja no campo da antropologia, das artes visuais ou da história, sobre o período colonial no Brasil e de como era a relação entre os colonizadores, os nativos e os escravos. O processo de dominação territorial e de exploração foi representado também em obras canônicas da nossa literatura, principalmente no romance indianista/ nacionalista, mesmo que de forma idealizada, que é o viés do projeto literário da escola romântica.

Mas mesmo diante de tanta abordagem sobre o Brasil colonial e das relações entre as três raças e todo o processo de violência e exploração por parte do colonizador europeu em relação as outras duas raças nos séculos que marcaram o período de "descoberta" e de estabilização dos portugueses por aqui, o que gerou episódios violentos de dizimação de povos inteiros em prol do suposto desenvolvimento da nova colônia portuguesa, uma questão parece escapar ou é muito pouco abordada pelos estudos mencionados que é a violência e a colonialidade de gênero. De fato, quanto a violência contra a mulher, temos abordagens relevantes sobre o assunto no campo da teoria, da crítica e mesmo da literatura, mas quando o que está em questão é a violência em relação ao sujeito gay dentro desse cenário, é preciso uma busca mais refinada, pois os estudos são mais pontuais, assim como a abordagem em relação as relações homoeróticas dentro desse período histórico.

Posto isto, o presente artigo tem como objetivo apresentar - mesmo que de forma breve e partindo de um objeto de estudo do campo ficcional - como se dava a violência de gênero contra os sujeitos homoafetivos no período colonial, sujeitos esses que na concepção de Judith Butler (1999) são denominados queers, ou ainda "ex-cêntricos", no conceito criado por Linda Hutcheon (1991), por não se enquadrarem no modelo binário, heteronormativo europeu imposto pela sociedade através da codificação da moral cristã.

Para tanto, partiremos de uma breve análise de dois casos citados no segundo romance e sexta obra do escritor e crítico literário paraibano Antônio de Pádua Dias da Silva, Tal Brazil, Queer Romance - Romance da(s) história(s) dos afetos ou História do(s) romances(s) dos afetos, publicada em 2012 pela Editora Scortecci, onde o autor apresenta, em uma narrativa metaficcional que mistura figuras reais da literatura e da história brasileira com personagens fictícias, situações de violência sofridas por sujeitos gays que acabam punidos de forma violenta pela sociedade e por representantes da igreja em nome da ordem, da religião e dos bons costumes. 


\section{Um Brasil queer desde a origem}

Tal Brazil, Queer Romance - Romance da(s) história(s) dos afetos on História do(s) romances(s) dos afetos, é uma metaficção historiográfica que parte de figuras históricas, fictícias e heroicas da literatura e da história do Brasil, como o missionário Padre Antônio Vieira, o poeta Tomás Antônio Gonzaga e sua personagem Marilia (da obra poética arcadista Marília de Dirceu), o poeta ultrarromântico Álvares de Azevedo, o romancista Aluízio Azevedo e o poeta barroco Gregório de Matos, interpretando as relações de gênero entre tais figuras e as personagens criadas por Pádua. O título do romance faz referência direta à obra crítica Tal Brasil, qual romance? (1984), dissertação de mestrado de Flora Sussekind, orientada pelo professor, poeta e ensaísta Silviano Santiago na qual a autora esboça a investigação e problematização da noção do Naturalismo como sinônimo de documentalismo, de observação fiel da realidade.

Pádua também propõe uma problematização em seu romance, mas diferente de Sussekind - que o faz pelo viés do ensaio - ele utiliza a narrativa ficcional. Trata-se de um romance de temática homoerótica, como as demais obras do autor, mas com o diferencial de que pela primeira vez traz para sua narrativa uma abordagem onde o ficcional se relaciona com fatos históricos para apresentar o drama vivenciado por suas personagens, tendo como pano de fundo o cenário do país ainda em seu período colonial, no que chamamos na historiografia da literatura brasileira de Era colonial, evidenciada pelas figuras históricas escolhidas pelo autor para compor a narrativa, que transitam do Quinhentismo, perpassando o Barroco, o Arcadismo até chegar ao Romantismo, primeira escola da Era nacional da nossa literatura.

A obra se divide em duas partes, nas quais a primeira se fixa, em seus nove capítulos, na tese de que o Brasil é um país queer desde sua origem. Já a segunda parte, que conta com sete capítulos, volta seu olhar para figuras femininas que transitam entre gêneros, se apresentando como ambivalentes. Para este estudo em questão, nos interessa a primeira parte da obra, da qual destacaremos os capítulos "No princípio de tudo era Brazil" e "Sobre Gregório de Matos e a sáfica Maribonda" para falarmos da violência de gênero e da colonialidade de gênero, com base na concepção de María Lugones (2008) sobre o termo. Antes de entrarmos nos capítulos em questão, nos debruçaremos primeiro nos conceitos para entendermos melhor a abordagem que pretendemos dar ao objetivo deste texto em detrimento ao objeto de estudo em tela. 


\section{A metaficção historiográfica}

Em sua obra Poética do pós-modernismo: história, teoria, fiç̧ão (1991), Linda Hutcheon define o que vem a ser uma metaficção historiográfica. Para a autora, até o século XIX a literatura e a história eram consideradas pertencentes ao mesmo campo de saber. A diluição de tal aproximação marca o pós-modernismo, ao utilizar-se do passado para questioná-lo, problematizá-lo. Nesse âmbito surgem as metaficcções historiográficas, romances autorreflexivos que se apropriam de acontecimentos e personagens históricos para questionar o passado histórico. Portanto, uma obra é considerada metaficção historiográfica quando possui

caráter de autorreflexividade intensa e, ao mesmo tempo, referências explícitas a personagens e eventos históricos; a junção de reflexões literárias, históricas e teóricas; o trabalho de subvertê-las; e a defesa de que, apesar de não negar a existência da história, o passado só nos é acessível por meio da textualidade (HUTCHEON, 1991, p. 141).

Nesse sentido, as metaficções historiográficas visam tecer críticas àquilo que ficou cristalizado pela história como verdade absoluta, buscando desmistificar o passado, denunciando seu lado nefasto e trazendo à tona tudo que foi escondido pelos processos de higienização e de apagamento histórico. Essa denúncia e crítica se dão, muitas vezes, através de personagens subalternos, considerados minorias, aqueles que como já mencionamos não estão de acordo com os padrões pré-estabelecidos pela normatização branca, heteronormativa, patriarcal e falocêntrica. Enquadram-se nesse perfil de minorias e subalternas as personagens queers e ex-cêntricas que Pádua apresenta em seu romance. Em suma, as metaficções historiográficas permitem, na inversão dos papéis e do protagonismo histórico, que passa a ser dos sujeitos subalternos, a contestação dos fatos históricos. Veremos agora quem são esses sujeitos.

\section{O sujeito queer e ex-cêntrico}

Segundo Guacira Lopes Louro em Teoria queer - uma politica pós-identitária para a educaşão, de 2001, o termo queer pode ser traduzido como "estranho" ou "ridículo" ou ainda como "excêntrico", tradução essa que nos remete ao termo criado por Linda Hutcheon, que explicaremos em seguida. Mas ainda em relação ao vocábulo queer, é uma forma pejorativa utilizada para se referir aos homens e mulheres homossexuais, um insulto, que segundo Judith Butler passou a ser utilizado para englobar grupos que se enquadram à comunidade LGBTQIA+, ressignificando o termo que outrora era uma injúria, revertendo sua conotação original. Segundo Guacira Lopes Louro (2001) 
Para esse grupo, queer significa colocar-se contra a normalização - venha ela de onde vier. Seu alvo mais imediato de oposição é, certamente, a heteronormatividade compulsória da sociedade; mas não escaparia de sua crítica a normalização e a estabilidade propostas pela política de identidade do movimento homossexual dominante. Queer representa claramente a diferença que não quer ser assimilada ou tolerada e, portanto, sua forma de ação é muito mais transgressiva e perturbadora (LOURO, 2001, p. 546).

Como mencionamos umas das traduções para o termo queer é "excêntrico", o que nos leva novamente à obra Hutcheon (1991), onde no capítulo 4, intitulado "Descentralizando o pós-moderno: o ex-cêntrico", vemos a autora cunhar o termo ex-cêntrico (ou off-centro) para se referir ao sujeito que se identifica "com o centro ao qual aspira, mas que lhe é negado" (HUTCHEON, 1991, p. 88). Ou seja, aquele sujeito que está à margem da sociedade e das normas pré-estabelecidas por ela, que são rechaçados pela normatização de atos, costumes e gostos e pela padronização dos afetos, dos corpos e dos desejos. Nesse sentido, as personagens homoeróticas do romance de Pádua representam exatamente essa figura do sujeito off-centro, cuja a marginalidade e a "ex-centricidade" (HUTCHEON, 1991) não é permitida e, em nome da lei, da igreja e dos bons costumes, são violentamente punidos, o que veremos a seguir.

\section{A colonialidade e a violência de gênero}

Entrando finalmente na obra de Pádua, no capítulo que abre o romance, intitulado "No princípio de tudo era Brazil", somos apresentados ao personagem António Bentes, filho bastardo do Padre Antônio Vieira, consagrado autor do barroco brasileiro graças aos seus sermões. Bentes, ao completar seus catorze anos, veio nas embarcações portuguesas para a colônia para ficar sob a tutela do padre após o suicídio da mãe, Ana Bolena, que não suportou o sacrilégio e "o gordo pecado que lhe pesava às costas” (PÁDUA, 2012, p. 14), ou seja, o caso de amor com o pároco, o que apesar de ser uma ficção, uma vez que nem Ana Bolena, nem Antônio Bentes são personagens históricos reais, diz muito do peso moral que recaia sobre as mulheres da época.

Entretanto, não é nem Ana Bolena, nem António Bentes que nos interessam aqui, mas sim o relato que o jovem Bentes faz de dois primos que foram flagrados "a desenhar em gestos e atitudes o entregar-se ao outro" (PÁDUA, 2012, p. 16). Eram Praxedes e Joaquim, que sendo primos, foram criados juntos. Depois que o primeiro retorna das batalhas ao Norte da África, aos vinte e cinco anos, encontra o Joaquim entregue à bebida em uma taverna. Uma paixão súbita e ardente toma conta dos dois, que acabam se entregando ao desejo que os consome 
Tiram as roupas numa pressa quase mortal. Sentem que são iguais em corpo, sexo e desejo. Entram um no outro sem nunca antes terem tido lição de amor para iguais. A forma como o gozo chega assemelha-se a aberrações pervertidas pelo muito do grito de ambos que ejaculam ao mesmo tempo sem saber que o segredo do desejo é escondido naquele instante que provoca outros momentos, que dá sentido e vontade de voltar a tê-lo, de lutar por ele e pelo outro, de querer ser feliz à luz daquilo que se sente (PÁDUA, 2012, p. 18).

No trecho em destaque, temos o momento da consumação do ato prazeroso, mas ao mesmo tempo pecaminoso, uma vez que ia contra todas as convenções morais e religiosas, uma transgressão passível de pena de morte, que é o que se segue na narrativa, em uma sequência violenta que começa com o flagrante dado através de uma denúncia até a condenação e punição dos primos amantes

\footnotetext{
Havia tido uma denúncia e eles foram flagrados em meio ao término do ato pecaminoso. Representantes da Igreja, da Família; o suserano, vizinhos. Curiosos e outros que ali acorreram para tomar como exemplo o que aconteceria àqueles dois: não seriam perdoados [...] As chamas das tochas perdiam o seu fulgor à luz do clarão do dia [...] O clero todo em negro [...] flagrados e condenados [...] Nos autos da Igreja: a voz pomposa que garantia a autoridade [...] Missão cumprida e Ordem estabelecida [...] A imagem dos dois primos julgados e condenados à Fogueira Santa o consumia. (PÁDUA, 2012, p. 18-19).
}

A inquisição era o método de punição mais recorrente da Igreja Católica para o chamado "pecado nefando sensual". Mas não era o único meio de punição para os sujeitos tidos transgressores da moral e dos costumes, como podermos ver no capítulo intitulado "Sobre Gregório de Matos e a sáfica Maribonda", onde Pádua nos relata o fim trágico de personagem que intitula o capítulo, uma bela negra "que se deitava com mulher como se homem fosse" (PÁDUA, 2012, p. 40) e que havia despertado o interesse do poeta barroco, mas, aconselhada pela amiga Luiza Sapata, não havia se entregado aos seus gracejos, mesmo diante de tantas investidas. Maribonda também foi alertada por Sapata que parte dos moradores de Salvador estava a sua busca, pois queriam "apedrejar Maribonda para que aprendesse a deixar de ser desavergonhada, procurasse um casamento para si e deixasse as mulheres, solteiras e casadas, em paz” (PÁDUA, 2012, p. 40).

Luiza Sapata então planeja a fuga da amiga para bem longe daqueles que se amontoavam "em nome de um Deus ausente e desconhecido, inexistente, mas vivo, muito vivo, bastante vivo" (PÁDUA, 2012, p. 40) Todavia, a fuga de Maribonda foi frustrada, e quem narra a sequência da captura e do assassinato da personagem é um Gregório de Matos perplexo 


\begin{abstract}
Não dava para perceber o que havia sido, mas em poucos segundos percebi do que se tratava, ao que meus pensamentos se negavam a acreditar naquilo que os olhos viam. As pernas bambas, lentamente, caíam ao se negar a ficar em pé. À medida que desfalecia, percebia que a matéria caída tinha sido a cabeça de Maribonda que havia sido atingida por um objeto de aço e muito cortante: atingira ao pescoço da mulher que teve o corpo separado da cabeça. Esta caiu há alguns metros atrás e o corpo conseguiu alcançar mais uns cinco metros antes de cair de vez à minha frente (PÀDUA, 2012, p. 40).
\end{abstract}

A violência com a qual se deu a morte da personagem é uma reação direta daqueles que não suportavam a transgressão de Maribonda, "a negra que ameaçou o sistema patriarcal, heterossexual e falocêntrico daquele lugar bastante desenvolvido" (PÁDUA, 2012, p. 43).

A partir dos dois casos apresentados e que compõem a narrativa do romance de Pádua, podemos observar que a violência em relação ao gênero está presente na sociedade desde seus tempos mais remotos. Essa violência histórica parte de um pressuposto que as transgressões de minorias como negros, mulheres e homossexuais deveriam ser punidas pelo sistema patriarcal ou pelos colonizadores, o que nos leva a concepção de colonialidade de gênero, termo criado pela socióloga e ativista feminina argentina María Lugones em Colonialidad y Género (2008) onde a autora apresenta três tipos de colonialidades: a do poder, a do saber e a do ser, para elaborar a ideia de colonialidade de gênero.

Lugones investiga no texto a intersecção entre raça, classe, gênero e sexualidade na tentativa de entender a indiferença dos homens em relação às violências que mulheres de cor sofrem. Essas mulheres são vítimas da colonialidade do poder e da colonialidade de gênero. A socióloga quer entender como esses homens que também são vítimas da dominação racial e da colonialidade de poder podem ser indiferentes à violência contra a mulher por parte do Estado e do patriarcado branco.

Lugones irá afirmar no texto que existem barreiras instransponíveis criadas pela indiferença em relação a violência sofrida pelas mulheres de cor e que apesar de hoje haver lutas de feministas de cor em torno da abordagem e revelação quanto às explorações violentas, elas não são suficientes para fazer com que os homens de cor, que também são vítimas, percebam que de certa forma acabam sendo cúmplices e/ou colaboradores na efetivação da dominação violenta das mulheres de cor. Nesse sentindo, podemos refletir sobre o caso de negra Maribonda na obra de Pádua, perseguida por uma multidão que queria punir sua transgressão. Multidão essa composta também por homens negros. Maribonda era condenada, nesse contexto, por três motivos: por ser negra, por ser mulher e por ser lésbica. Condições que, ao olhar do colonizador, a faziam algo que inferior, subalterno. 
A autora ainda em seu texto explica que "mulheres" enquanto gênero, não é um termo definido pela biologia. A associação colonial entre anatomia e gênero é parte da oposição binária e hierárquica. O surgimento de mulher como uma categoria reconhecível, definida anatomicamente e subordinada ao homem em todo tipo de situação, é resultado da imposição de um estado colonial patriarcal. E para essas mulheres, a colonização foi um processo duplo de inferiorização racial e subordinação de gênero. A autora afirma que uma das primeiras conquistas do estado colonial foi a criação de tal categoria, "mulheres". Mesmo assim, as fêmeas "não-brancas" eram consideradas animais "sem-gênero" (LUGONES, 2008), sendo subordinadas e destituídas de poder

\footnotetext{
Las hembras excluidas por y en esa descripción no eran solamente sus subordinadas sino también eran vistas y tratadas como animales, en un sentido más profundo que el de la identificación de las mujeres blancas con la naturaleza, con los niños, y con los animales pequeños. Las hembras no-blancas eran consideradas animales en el sentido profundo de ser seres «sin género»23, marcadas sexualmente como hembras, pero sin las características de la femineidad (LUGONES, 2008, p. 94).
}

Segundo Lugones, as fêmeas racializadas como seres inferiores foram transformadas de animais a diferentes versões de mulher, "en tantas versiones de 'mujer' como fueron necesarias para los procesos del capitalismo eurocentrado global.” (LUGONES, 2008, p. 94). Ao ler o texto de Lugones e suas considerações sobre o olhar do colono em relação às mulheres negras, vai se evidenciando que a violência de gênero, de raça e de orientação sexual partiu de um processo de colonização do ser, tido como marginalizado, como inferior e que permanece ainda nos dias atuais, pois ainda existe o discurso que segrega o que estamos chamando aqui, às luzes de Butler e Hutcheon, de sujeitos queers e ex-cêntricos. Os séculos se passaram, mas o preconceito e a violência permanecem muito presentes.

Nesse sentido, existiu um processo de inferiorização e objetificação das minorias que sofreram a violência do colonizador e do patriarcado, processo esse que ainda se faz presente na sociedade atual. Em vários momentos da obra de Pádua, temos situações em que as personagens sofrem com a colonialidade e a violência daqueles que não aceitam as suas "transgressões", suas identidades de raça e de gênero.

Desta forma, o romance de Pádua cumpre com a problematização do passado que Hutcheon afirma ser a tônica do romance metaficional historiográfico, uma vez que apresenta a relação de suas personagens fictícias com personagens históricas para problematizar a violência contra os sujeitos queers no cenário de Brasil colonial, sem medo de ser anacrônico em relação ao termo, tendo em vista que ele é contemporâneo, mas sabendo que os sujeitos considerados 
"estranhos" ou "excêntricos" para os padrões sociais pré-estabelecidos sempre existiram, e que é preciso pensar como foram tratados pela sociedade no passado, para entendermos como ainda são tratados nos dias atuais. Esta é a função do estudo de gênero, a função da metaficção historiográfica e a função de quem se propõe a problematizar a história, indo além do que ela nos é apresentada em textos higienizados, sendo os literários, sendo os didáticos.

\section{Considerações finais}

Como vimos, a violência de gênero é histórica e está ligada ao que Lugones entende como colonialidade de gênero, onde as minorias são vistas como sujeitos subalternos ao padrão branco, patriarcal, heteronormativo e binário, que vê como queers ou ex-cêntricos, nos termos de Butler e Hutcheon, esses sujeitos que transgridem o modelo pré-estabelecido pela sociedade através de seus costumes e crenças, independente do período histórico em tela, uma vez que passados séculos desde as inquisições da Santa Igreja na colônia até os dias atuais, a violência de gênero ainda é uma dura realidade que vitima mulheres e homossexuais no Brasil.

Segundo dados levantados pelo Grupo Gay da Bahia, divulgados no dia 14 de maio de 2021, ocorreram 237 mortes violentas de sujeitos gays em 2020 no Brasil. Foram 224 homicídios e 13 suicídios. Já de acordo com a Rede de Observatório de Segurança em pesquisa denominada "A Dor e a Luta: Números do Feminicídio", apontam que pelo menos cinco mulheres foram assassinadas ou vítimas de violência por dia em 2020. Esses dados só corroboram com a afirmação de Hutcheon em relação à necessidade de problematizar o passado para se entender o presente. Fica a esperança de que a violência de gênero um dia seja um triste fato do passado, registrada apenas nos livros históricos ou literários.

\section{Referências}

BUTLER, Judith. "Corpos que pesam: sobre os limites discursivos do 'sexo"'. In: LOURO, Guacira Lopes (Org.). O corpo educado: pedagogias da sexualidade. Belo Horizonte: Autêntica, 1999. p. 151-172.

BUTLER, Judith. Criticamente subversiva. In: JIMÉNEZ, Rafael M. Mérida. Sexualidades transgresoras. Una antología de estudios queer. Barcelona: Icária editorial, 2002.

BUTTURI JUNIOR, Atilio. Os discursos sobre a homossexualidade brasileira no período colonial. Acta Scientiarum. Language and Culture, Maringá, v. 35, n. 1, p. 143152, Apr.-June, 2013. 
DEL PRIORE, Mary. Ao Sul do Corpo: Condição feminina, maternidades e mentalidades no Brasil Colônia. Rio de Janeiro, RJ: José Olímpio; Brasilia, DF: Edunb, 1993.

DEL PRIORE, Mary. História das mulheres: As vozes do silêncio. In: FREITAS, Marcos César (Org.). Historiografia Brasileira em Perspectiva. 3 ed. São Paulo, SP: Contexto, 2000.

GARCIA, Paulo César; MIRANDA, Olinson Coutinho. A teoria Queer como representação da cultura de uma minoria. Comunicação III EbeCult encontro Baiano de Estudos em Cultura, UFRB, 2012.

HUTCHEON, L. Poética do pós-modernismo: história, teoria, ficção. Rio de Janeiro: Imago, 1991.

JUCÁ, Julyanne. Por dia cinco mulheres foram vítimas de feminicídio em 2020, aponta estudo. CNN Brasil. São Paulo. 04/03/2021 às 16:15. Disponível em: https://www.cnnbrasil.com.br/nacional/por-dia-cinco-mulheres-foram-vitimas-de-feminicidio-em-2020, consultado em 27 de agosto de 2021.

LIMA, Sérgio. Relatório registra 237 mortes violentas de pessoas LGBTs no Brasil em 2020. Poder360. Brasília. 16.mai.2021 (domingo) - 15h23. Disponível em: https:// www.poder360.com.br/brasil/relatorio-registra-237-mortes-violentas-de-pessoas-lgbts-no-brasil-em-2020/, consultado em 27 de agosto de 2021.

LOURO, Guacira Lopes. Teoria queer - uma política pós-identitária para a educação. Revista Estudos Feministas [en linea]. 2001, 9(2), 541-553. ISSN: 0104-026X. Disponível em: https://www.redalyc.org/articulo.oa?id=38109212, consultado em: 29 de agosto de 2021.

LUGONES, María. Colonialidad y Género. Tabula Rasa. Bogotá - Colombia, n.9, 73101, julio-diciembre 2008.

PÁDUA, Antonio de. Tal Brazil, queer romance: romance da (s) história (s) dos afetos ou história (s) do (s) romance (s) dos afetos. São Paulo: Scortecci, 2012.

PEIXOTO, Valdenízia bento. Violência contra LGBTS no Brasil: a construção sócio-histórica da abjeção dos corpos. Anais do $16^{\circ}$ Encontro Nacional de Pesquisadores em Serviço Social.

SÜSSEKIND, Flora. Tal Brasil, Qual romance? Uma ideologia estética e sua história: o naturalismo. Rio de Janeiro: Achiamé, 1984. 